\title{
Breve reflexão sobre os últimos 25 anos da Indústria Química em Portugal*
}

\author{
CLEMENTE PEDRO NUNES**
}

Para se preparar o futuro com profundidade estratégica, é necessário analisar o passado recente a fim de nele descobrir as principais linhas de força que estão na origem das grandes questões que irão determinar esse mesmo futuro.

No caso da indústria química, aqui entendida no seu sentido mais amplo, que inclui as indústrias de todos os tipos que utilizem de forma apreciável reacções ou processos de engenharia química, esta tem em Portugal uma importância significativa e sofreu no último quarto de século uma evolução rica de acontecimentos, parecendo, pois, ser a altura de sobre ela fazer uma reflexão que nos permita clarificar a nova etapa que agora se inicia no contexto do Mercado Único Europeu.

\section{O QUE É A INDÚSTRIA}

Uma vez que se pretende analisar a indústria química no seu sentido lato, clarifiquemos um pouco os conceitos e as realidades de que estamos a tratar.

Partindo da definição académica mais ampla que considera como indústrias químicas aquelas em que "a matéria é tratada para se efectuarem mudanças de estado, de conteúdo energético ou de composição química" nela se incluem não só as indústrias de sinteses e reacções químicas, mas também as indústrias agro-alimentares, as indústrias farmacêuticas e de cosméticos, a fileira florestal-celulose-papel, a indústria cimenteira e mesmo outras indústrias mais de "fronteira" com a própria siderurgia e as indústrias de processos ligadas à exploração mineira e à metalurgia de base.

Trata-se, pois, dum vastíssimo sector industrial, englobando unidades de grande dimensão articuladas com outras de pequena e média dimensão constituindo no seu conjunto uma extensa malha de grande impacto no âmbito da economia portuguesa.

\section{A INDÚSTRIA QUÍMICA EM PORTUGAL EM MEADOS DA DÉCADA DE SESSENTA}

Reforçada pelos importantes investimentos efectuados desde os finais da década de 50 , a indústria química apresentava-se como um dos motores do desenvolvimento económico do País.

Assim, nesse período, tinham-se feito em Portugal importantes investimentos nesta área que incluíram 0 início da produção de amoníaco petroquímico e de nitratos, o reforço da produção de ácido sulfúrico com as então recentes tecnologias de contacto, 0 arranque de polímeros petroquímicos de PVC baseado na produção de VCM carboquímico nacional, 0 alargamento da produção de derivados de sódio na Soda Póvoa e arranque e produção de cloro e soda electrolitica em Estarreja.

Noutras áreas o desenvolvimento era também intenso:

- na celulose arranca em 1961 a fábrica de Constância com pasta de bissulfito, e em 1964 a fábrica de Setúbal, com pasta de sulfato;

- na indústria cervejeira entra em laboração a nova unidade de Leça do Balio, junto ao Porto, de grande dimensão e características inovadoras para a época;

- na refinação de petróleo, após o aumento de capacidade de Cabo Ruivo em 1956, para 1,2 milhões de toneladas, é autorizada a construção da refinaria do Norte, em Matosinhos.

A indústria química passava, assim, duma certa "adolescência" que a caracterizava para um "amadurecimento". Embora a esmagadora maioria dos equipamentos industriais relevantes fossem projectados e importados do estrangeiro, a instalação e arranque das unidades eram acompanhados e muitas vezes dirigidos por engenheiros portugueses, começando a desenvolver-se, sobretudo na Companhia União Fabril, o gosto pelo projecto autónomo de instalações e equipamentos industriais, em especial na área da química inorgânica pesada.

\section{PERÍODO DE 1966 A 1973: A ÉPOCA DOS GRANDES PROJECTOS}

0 período desenvolvimentista já anteriormente verificado, a par dum alargamento dos mercados interno e externo, com a consolidação do papel de Portugal na EFTA (Associação Europeia de Comércio Livre liderada pelo Reino Unido e países nórdicos), veio dar um grande impulso à indústria quimica dentro dum quadro orientador definido nessa época pelo Estado no âmbito dos Planos de Fomento.

Assim, em 1969, inicia a produção a refinaria de Matosinhos, com uma capacidade de destilação de 2 milhões de toneladas/ano, dotada ainda duma moderna unidade de óleos lubrificantes, e logo em 1970 a refinaria de Cabo Ruivo, junto a Lisboa, é ampliada também para 2 milhões de toneladas/ano de destilação, passando a refinaria a incluir dez unidades diferentes a jusante.

Todavia, face aos crescentes consumos de derivados de petróleo registados no mercado português e europeu, e ao facto do Canal do Suez estar encerrado desde 1967 na sequência da Guerra dos Seis Dias, o que passou a privilegiar a rota do Cabo da Boa Esperança em detrimento do Mediterrâneo, 0 Governo decide autorizar 0 aumento da refinaria de Matosinhos para 5 milhões t/ano e, através do Decreto-Lei 270/71, aprovar a a instalação duma grande refinaria e dum complexo petroquimico de olefinas em Sines.

Em articulação com a decisão relativa ao pólo de Sines, e tendo certamente uma preocupação de equilíbrio regional, é aprovado ainda em Novembro de 1971 0 estudo da instalação duma petroquímica de aromáticos em Estarreja ou Matosinhos, e cuja concretização seria levada a cabo através duma colaboração entre a SACOR e o Amoníaco Português. Para dar corpo a este projecto é autorizado novo aumento da refinaria de Matosinhos, desta vez para 7,5 milhões de t/ano de destilação e seis unidades a jusante. 
OS QUATRO GRANDES PERIODOS CONSIDERADOS NOS ÚLTIMOS VINTE E CINCO ANOS DA INDÚSTRIA QUÍMICA EM PORTUGAL

\begin{tabular}{l|l}
\hline 1966 a 1973 & Os grandes projectos \\
1974 a 1978 & $\begin{array}{l}\text { O primeiro choque petrolifero, a recessão económica e as } \\
\text { transformações empresariais }\end{array}$ \\
1979 a 1984 & O relançamento frustrado \\
1985 a 1992 & A crise e a adaptação às novas realidades \\
\hline
\end{tabular}

Por detrás desta estratégia global de desenvolvimento económico estava também o princípio tendencial duma possivel auto-suficiência petrolifera nacional baseada na produção de Cabinda e do Norte de Angola, então sob administração portuguesa.

0 ano de 1971 marcou, pois, o culminar das expectativas anteriores e a consolidação do plano para converter a indústria química pesada no motor, por excelência, do desenvolvimento industrial e económico de Portugal. Foi um momento de sonho de grandeza cuja análise profunda ainda não está feita, mas que está longe de ter sido um ponto avulso no tempo como alguns críticos mais radicais vieram mais tarde a afirmar sem um estudo suficientemente profundo das opções estratégicas então tomadas, bem como das condicionantes que a partir de 1973/74 toda a indústria química pesada portuguesa passou a sofrer de forma muito intensa e gravosa.

A par destes grandes projectos surgem outros importantes desenvolvimentos industriais:

- construção duma unidade de ácido nítrico em Estarreja com capacidade de 110000 t/ano, cujo arranque se vem já a dar em 1974, articulada com a produção a jusante de nitrato de amónio e adubos;

- arranque em Alverca da segunda fábrica de ácido nítrico em 1968, a par com a ampliação das unidades ai instaladas de adubos azotados;

- nas celuloses arrancam as unidades da CELBI na Figueira da Foz em 1965 e a unidade da CELTEJO em Vila Velha do Ródão em 1971;

- em 1968 é inaugurada a nova fábrica de cervejas e refrigerantes de Vialonga, próximo de Lisboa;

— em 1969 inicia a laboração a primeira grande fábrica portuguesa de antibióticos, a CIPAN, junto ao Carregado;
- a indústria de concentrados de tomate tem nesta altura um grande desenvolvimento, passando a exportar quantidades apreciáveis para outros paises europeus, nomeadamente da EFTA;

- em 1973 inicia-se o fabrico de cimentos da CISUL, em Loulé, no Algarve, e, em 1974, da CINORTE, em Souselas, próximo de Coimbra.

\section{PERÍODO DE 1974/78: O PRIMEIRO CHOQUE PETROLÍFERO, A RECESSÃO ECONÓMICA E AS TRANSFORMAÇÕES EMPRESARIAIS}

Em Outubro de 1973, na sequência da guerra de Yom Kippur, é declarado um embargo petrolífero aos países ocidentais, seguido da quadruplicação dos preços do petróleo dos paises exportadores da OPEP.

Após alguma perplexidade inicial, 0 ano de 1974 confirma que a OPEP consegue impôr, como cartel produtor, o novo preço do petróleo, o que origina não só um profundo desequilíbrio das balanças de pagamento dos países europeus, como altera os pressupostos dos projectos efectuados no período anterior em Portugal, nomeadamente na química orgânica pesada, toda ela baseada no petróleo.

A análise fria e ponderada das consequências do que se estava a passar, em termos da revisão da anterior estratégia de desenvolvimento industrial em Portugal, foi todavia seriamente prejudicada pelas profundas transformações políticas que o País então atravessou, e que alteraram drasticamente 0 anterior quadro da gestão industrial através das nacionalizações então decididas. Note-se que a indústria química foi particularmente afectada por este processo:

- nacionalização da CUF, dos Nitratos de Portugal e do Amoníaco
Português, posteriormente fundidas em 1978 numa única empresa, a QUIMIGAL;

- nacionalização da SACOR, da SONAP e da PETROGAL, posteriormente fundidas numa única empresa, a PETROGAL;

- nacionalização da Companhia Portuguesa de Celulose, da SOCEL, da CELTEJO, da CELNORTE e das Celuloses do Guadiana, todas elas integradas de seguida numa nova empresa, a PORTUCEL;

- nacionalização da Empresa de Cimentos de Leiria, da Cimentos Tejo, da CISUL e da CINORTE, dos Cimentos do Cabo Mondego, posteriormente integradas numa única empresa, a CIMPOR; Nacional;

- nacionalização da Siderurgia

— nacionalização das três grandes empresas cervejeiras portuguesas.

Note-se que além das empresas foram "nacionalizados" os dois "projectos" mais emblemáticos do período anterior: a Companhia Nacional de Petroquímica, com 0 seu grande projecto dum "steam-cracker" de olefinas e polímeros a jusante, e o projecto de petroquímica de aromáticos integrado em parte na nova PETROGAL e em parte no Amoníaco Português, posteriormente integrado na QUIMIGAL.

- E, perguntar-se-á, que se decidiu fazer no âmbito das realidades concretas da gestão industrial, para adaptar as empresas à nova realidade internacional?

A construção da refinaria da PETROSUL, em Sines, já em curso em 1973/74 prosseguiu sensivelmente de acordo com os planos iniciais, apenas afectados pelos atrasos inerentes aos conflitos sociais então verificados, vindo a arrancar em 1978.

0 projecto da petroquímica de aromáticos iniciou a sua concretização com a produção de mononitrobenzeno e anilina em Estarreja, já então no âmbito da QUIMIGAL. 0 seu abastecimento veio a ficar dependente, numa primeira fase, da importação de benzeno através do terminal de Aveiro.

Este início de consumo de aromáticos em Portugal veio dar um impulso estratégico decisivo que ultrapassou as hesitações eventualmente existentes e fez avançar com a construção da unidade de BTX junto à refinaria de Matosinhos.

Quanto ao caso do projecto da petroquímica de olefinas, baseada num "steam-cracker" com capacidade de pro- 
dução de 200000 t/ano de etileno, a evolução é mais interessante. A revisão dos parâmetros a que se procedeu em 1974 e 1975 levou a que fosse definido em 1976 (por decisão governamental!) o aumento da capacidade do "steam-cracke" de 200000 para 300000 t/ano e a construção de mais 18 unidades a jusante do que as 6 inicialmente previstas, bem como todas as infra-estruturas de apoio, incluindo uma central térmica de $70 \mathrm{MW}$. Procurava-se ganhar no efeito de escala 0 equilíbrio perdido, ignorando-se as realidades do mercado consumidor a jusante.

Todavia a construção do complexo nestes novos parâmetros foi iniciado e em 1978 encontrava-se já num ponto dificimente reversivel. $A$ atestar esta tendência e confirmando de certa maneira a capacidade do Estado de levar à prática, embora com considerável atraso, os grandes projectos que o sector privado tinha em mãos antes da crise de 1973/74, arrancava em Sines em 1978/79 a grande refinaria da PETROGAL, com capacidade para processar dez milhões de t/ano de petróleo bruto, passando assim o País a ser largamente excedentário em termos da capacidade de refinação.

\section{PERÍDD DE 1979/84. O RELANÇAMENTO FRUSTADO}

0 início de 1979 marcou assim um ponto de viragem nos grandes investimentos previstos na indústria química pesada; após um periodo de atrasos e algumas indefinições que se arrastaram por cerca de quatro anos, o desenvolvimento industrial por que o País ansiava, para poder melhorar os seus padrões económicos e propiciar empregos melhor remunerados, voltava a basearse na revitalização e conclusão dos projectos anteriores a 1973/74.

Para esta redinamização contribuiram também o relativo sucesso da aplicação do primeiro programa de estabilização do FMI e uma certa retoma económica a nivel internacional.

Neste quadro arranca em 1981 a petroquímica de aromáticos da PETROGAL em Matosinhos, cujo benzeno passa a alimentar as unidades de mononitrobenzeno/anilina da QUIMIGAL em Estarreja, e em 1982 inicia a laboração o "steam-cracker" da Companhia Nacional de Petroquímica em Sines que, todavia, só viria a estabilizar a sua produção a partir de 1984, devido a problemas técni- cos e comerciais que se foram arrastando. Tal não impediu 0 arranque em 1982. das unidades de polietileno de alta densidade, polietileno de baixa densidade e de polipropileno, todas da EPSI.

Para além da concretização destes projectos já antigos, é neste período, e sobretudo entre 1979 e 1981, que se dá a ilusão da possibilidade dum relançamento da indústria química nos mesmos moldes de gestão estratégica que haviam caracterizado o final dos anos sessenta.

Registemos alguns factos que confirmam esta apreciação:

- prosseguimento pela QUIMIGAL da construção da unidade de peletização de cinzas de pirite (conhecida como unidade Kowa Seiko), instalada no Barreiro, que viria a arrancar em 1981/82 para encerrar poucos meses depois por falta de viabilidade económica;

- construção de unidades de polióis, resinas de poliéster, poliuretanos, plastificantes e fibra de vidro também pela QUIMIGAL no Barreiro, com inicio de produção também em 1981;

- aprovação da construção em 1982 da unidade de ftalatos pela então Petroquímica e Gás de Portugal em Cabo Ruivo, aumentando assim a integração a jusante dos aromáticos pelo consumo de ortoxileno;

— dado que a subida das cotações internacionais da nafta química tornara inviável a produção de amoníaco a partir desta matéria-prima, é aprovada em 1980 a instalação duma grande fábrica de amoníaco pela QUIMIGAL no Lavradio, a partir de resíduos de vácuo, com capacidade para 220000 t/ano, o que iria permitir 0 encerramento de todas as unidades então existentes;

- para aumentar o valor acrescentado em Portugal a jusante dos aromáticos/anilina, estabeleceu-se uma "joint-venture" entre a QUIMIGAL e a UPJOHN para a produção de 50000 t/ano de isocianatos em Estarreja; esta unidade iniciou laboração em 1982.

Todos estes investimentos, de que o Estado foi o agente único ou dominante, padeceram, em retrospectiva, de dois graves erros de avaliação estratégica:

a) não foi salvaguardada a capacidade nacional de endogenizar as tecnologias utilizadas nem foi feito um esforço para gerir a capacidade de inovação tecnológica duma forma mais agressiva que anteriormente, tendo em vista 0 aumento da competitividade dos produtos finais em mercado aberto;

b) o mercado a jusante continuou a ser sobrevalorizado não tendo sido feito um esforço suficientemente rigoroso para adaptar as produções previstas à capacidade dos mercados nacional e internacional de as vir a absorver a preços compatíveis e em tempo útil.

É justo sublinhar que a "sorte dos deuses" em nada favoreceu este esforço de relançamento do investimento, e o segundo grande choque petrolífero de 1980/81, provocado pela queda do Xá do Irão e pela subida ao poder nesse país do fundamentalismo xiita, constituiu para toda a economia portuguesa um golpe profundo e devastador que a fez entrar em recessão profunda a partir de 1982/83.

Registe-se, todavia, que no período em análise também 0 sector privado ou, melhor dizendo, não-estatal, efectuou investimentos de algum vulto de que podemos salientar:

- entrada em funcionamento em 1984, perto da Figueira da Foz, da fábrica de celulose da SOPORCEL;

- a CIRES, produtora de resinas de PVC, aumenta em 1982 a sua capacidade global com 8500 t/ano de PVCemulsão;

- também em 1982 a UNITECA moderniza as células electrolíticas e aumenta a capacidade para 20000 toneladas/ano de soda cáustica.

\section{PERIODO DE 1985/92: A CRISE E A ADAPTAÇÃO ÀS NOVAS REALIDADES}

Os anos de 1984 e 1985 constituiram um período de dolorosa correcção dos desequilíbrios que se haviam gerado nas finanças públicas, tendo havido mais uma vez que se recorrer às "terapias de choque" do FMI.

Embora algumas grandes indústrias químicas como a CIMPOR, a PORTUCEL e a CIRES continuassem a registar situações financeiras desafogadas, outras, nomeadamente a QUIMIGAL, a Siderurgia Nacional, a Companhia Nacional de Petroquímica e mesmo a PETROGAL, enfrentavam dificuldades financeiras crescentes, com prejuízos acumulados e total incapacidade de fazer face às amortizaçōes dos investimentos efectuados no periodo antecedente.

0 Estado, como accionista, estava sem recursos financeiros para injectar as verbas necessárias, e a abertura comercial que uma adesão às Comunidades Europeias iria provocar punha em sérias dúvidas a própria viabilidade económica futura de empresas habituadas a movi- 
mentarem-se sobretudo num mercado restrito e protegido.

- De facto, foi uma ironia da nossa história industrial que um dos periodos em que o Estado português mais fortemente interveio directamente na actividade industrial (1975/1985), fosse seguido dum período (após 1986) de crescente desintervenção do Estado e de abertura das nossas fronteiras à Europa, como anteriormente nunca se havia verificado. Como choque entre diferentes perspectivas de enquadramento estratégico dificilmente se poderia ter tido um solavanco mais violento!

De entre as empresas em maior risco de soçobrar, três grandes empresas de processos químicos foram objecto de especial atenção do Estado:

- a QUIMIGAL;

- a Companhia Nacional de

Petroquímica/EPSI;

- a Siderurgia Nacional.

Enquanto a QUIMIGAL e a Siderurgia Nacional foram objecto de planos especiais de reconversão, a CNP/EPSI foi objecto dum processo de privatização por concurso que levou posteriormente ao seu controlo pela multinacional finlandesa Neste $0 y$.

Em qualquer dos casos o objectivo apresentava-se claro: tentar reconverter e tornar viáveis todas as unidades com um mínimo de capacidade concorrencial a nível dum mercado europeu aberto, eliminar todos os custos não essenciais e encerrar todas as unidades obsoletas.

Registe-se que, apesar dos graves problemas surgidos, a malha da indústria química nacional se tinha fortalecido bastante em termos produtivos e que 0 desafio era basicamente de optimização da gestão do parque industrial existente.

Simultaneamente as celuloses beneficiaram até 1990 duma conjuntura internacional muito favorável, tendo-se reconvertido em 1986 a unidade da PORTUCEL em Mourão, prosseguindo por outro lado a CIMPOR com resultados desafogados.

Noutras áreas da indústria quimica é de referir:

-0 arranque duma segunda grande unidade de produtos farmacêuticos de base, a HOVIONE;

- a reconversão tecnológica da produção de mononitrobenzeno/anilina com 0 arranque duma nova unidade de nitração adiabática, que veio tornar concorrencial a ANILINA DE PORTUGAL como nova empresa do Grupo QUIMIGAL;

- os aumentos de capacidade registados na CIRES e na UNITECA;

- 0 início da produção de novos compostos de sódio por parte da SODA PÓVOA.

Até final de 1992 o sector da indústria química estatal havia sido reduzido pela privatização parcial $(25 \%)$ do capital social da PETROGAL, pela privatização de várias empresas provenientes da completa reestruturação efectuada a partir de 1989 no Grupo QUIMIGAL (NUTASA, CUF Têxteis, LUSOL, PLASQUISA, LUSOFANE, SONADEL, TINCO e PREVINIL) e pela já referida privatização da CNP/EPSI.

\section{O FUTURO: OS DESAFIOS DO MERCADO ÚNICO EUROPEU}

A primeira pergunta que pode ressaltar a um observador atento desta breve viagem dum quarto de século à evolução da indústria química em Portual, é a seguinte:

- Se há 25 anos a indústria química estava a acabar a "adolescência", será que entrou entretanto numa "velhice precoce"?

Em mercado aberto a indústria química, como qualquer realidade empresarial, depende das oportunidades, dos factores competitivos e da inteligência que os seus dirigentes tiverem para enfrentar os novos desafios.

Situada na encruzilhada de tecnologias em permanente evolução, dotada dum vasto património produtivo, a indústria química em Portugal enfrenta todavia concorrentes poderosos, alguns dos quais situados no Próximo Oriente se têm vindo a desenvolver de forma acelerada nos últimos anos. Assim, o seu futuro depende, em primeiro lugar e como em nenhum outro sector, dum novo conceito de Gestão Industrial, que saiba integrar as potencialidades dos recursos humanos com preparação científica de alto nivel nas realidades empresariais existentes.

A urgência desta interacção, deste diálogo criativo, faz-se sentir de forma aguda desde pelo menos 1980 , quando se deu 0 relançamento atrás referido e que veio a ficar frustado. 0 futuro profissional dos jovens licenciados, mestres e doutores em Engenharia Química e em Química depende da evolução que tiver a Indústria Química mas, por outro lado, se eles não puderem ser mobilizados e não aceitarem o desafio que a Indústria Química Ihes coloca, o futuro desta será na melhor das hipóteses, medíocre.

- E como articular o perfil do gestor com o perfil do tecnólogo e do cientista?

Continuo a pensar, tal como quando me doutorei já há 17 anos, que nada de mais reconfortante para um investigador em engenharia do que poder ajudar a transformar os seus estudos em realidades concretas, em ferramentas de competitividade e optimização permanente de realidades industriais.

Um gestor industrial terá que saber transmitir esse espírito aos seus melhores técnicos sob pena de não estar a assegurar o futuro da sua empresa. 0 cientista e o tecnólogo que querem trabalhar numa empresa têm que compreender que o seu trabalho é definido em função da estratégia empresarial global para o qual ele dará um contributo que a maior parte das vezes é importante mas muitas vezes não é decisivo.

Se isto for bem compreendido em muitas indústrias químicas portuguesas, a inovação tecnológica competitiva terá nelas um lugar muito mais preponderante do que hoje tem, e as "batalhas industriais" aqui relatadas poderão ter no futuro mercado europeu, em que já entrámos, uma evolução globalmente mais positiva do que aquela que se verificou no último quarto do século.

\section{REFERÊNCIAS}

1. R. Guedes de Carvalho, "Alguns casos tipi$\cos$ da evolução da Engenharia Química em Portugal', Ingenium, 2 (1986) 57.

2. C. Pedro Nunes, 'A universidade e a indústria em Portugal: pistas para uma cooperação efectiva", Técnica, 42 (1981) 462.

3. C. Pedro Nunes, "Investigaçāo e Desenvolvimento no contexto da indústria química portuguesa: uma experiência*, Seminário sobre "O papel do Engenheiro Químico na Indústria", IST (1985).

4. C. Pedro Nunes, "A inovação tecnológica na indústria química em Portugal: algumas reflexões", Ingenium, 36 (1990) 68.

* Texto baseado na conferência proferida em Novembro de 1992 no Instituto Superior Técnico, integrada nas Jornadas de Inovação Tecnológica na Indústria Química ** Administrador da QUIMIGAL, S.A.;

Professor do I.S.T.; Coordenador do Colégio de Engenharia Química da Ordem dos Engenheiros/Região Sul 